\title{
Zonal Jet Structure and the Leading Mode of Variability
}

\author{
Scott J. Eichelberger And Dennis L. Hartmann \\ Department of Atmospheric Sciences, University of Washington, Seattle, Washington
}

(Manuscript received 26 June 2006, in final form 1 February 2007)

\begin{abstract}
An observational analysis of the Northern Hemisphere circulation during winter reveals that the leading mode of variability depends on longitude. In particular, the first EOF of the zonal-mean circulation differs over the Atlantic and Pacific sectors. These results provide motivation for a series of model runs where a simple GCM is used to investigate the effects of the zonal jet structure on the leading mode of variability in the Northern Hemisphere. Model results indicate that the leading mode of variability depends on the distance between the eddy-driven and subtropical jets. When the jets are well separated, the leading mode of variability describes latitudinal shifting of the eddy-driven jet. However, when the two jets are nearly collocated, pulsing of the combined jet dominates the variability. This change coincides with a weakening of the positive feedback between the eddies and zonal flow anomalies. These results provide a possible explanation for the reduced amplitude of the Northern Annular Mode in the Pacific sector relative to that in the Atlantic sector during Northern Hemisphere winter.
\end{abstract}

\section{Introduction}

The tropospheric zonal flow consists of two dynamically distinct jets: the subtropical jet and the midlatitude eddy-driven jet. To first order, the subtropical jet results from angular momentum transport by the Hadley circulation (Held and Hou 1980), which is driven by thermal convection. The subtropical jet exists at the poleward boundary of the Hadley circulation. The eddy-driven jet results from the eddy-momentum flux convergence of baroclinic waves that develop in a region of enhanced baroclinicity (Held 1975; Rhines 1975; McWilliams and Chow 1981; Panetta 1993). Eddydriven jets typically develop in midlatitudes because baroclinic eddies are most prevalent in midlatitudes, as seen by the time-mean location of storm tracks. The time-mean tropospheric zonal flow at most longitudes can be described in terms of the strength and position of these two jets.

Recently much progress has been made in understanding the variability of the zonal-mean state. Much of this research has been motivated by Gong and Wang (1999) and Thompson and Wallace (2000), who demonstrated that the structure of the leading mode of low-

Corresponding author address: Scott J. Eichelberger, 3TIER, 2001 6th Ave., Suite 2100, Seattle, WA 98121.

E-mail: seich@3tiergroup.com frequency variability in the Southern Hemisphere strongly resembles that in the Northern Hemisphere. This result was quite surprising considering the large differences between the two hemispheres in terms of topography and land-sea contrasts. Limpasuvan and Hartmann (1999) named these leading modes the Southern Annular Mode (SAM) and Northern Annular Model (NAM), collectively the annular mode, because of their near zonal symmetry. The annular mode is defined as the leading empirical orthogonal function (EOF) of geopotential height in the lower troposphere over the extratropics of either the Northern or Southern Hemisphere. In terms of the zonal-mean zonal wind, the annular mode describes latitudinal shifting in the position of the eddy-driven jet (Lorenz and Hartmann 2001, 2003).

Lorenz and Hartmann $(2001,2003)$ provide a thorough explanation of the eddy-zonal flow dynamics associated with the annular mode. Specifically, they demonstrate the existence of a positive eddy-zonal-mean flow feedback. The positive feedback between the eddies and the zonal wind anomalies accounts for the increased persistence and variance of the annular mode over other patterns of variability. Thus, the annular mode results as the leading mode of variability because the eddies reinforce the annular mode.

Many questions remain unanswered concerning the zonal asymmetries of the annular mode. In the South- 
ern Hemisphere the annular mode is nearly zonally symmetric, but the NAM exhibits strongest amplitude over the Atlantic sector with a weaker center of action over the Pacific sector. A dynamical explanation for this behavior does not exist and is the main investigation of this study.

The next section contains an analysis of Northern Hemisphere January-mean observational data that highlights the differences in the zonal jet structure and leading mode of variability over the Atlantic and $\mathrm{Pa}$ cific sectors. Results from the observational analysis provide motivation for a series of model runs described in section 3. The numerical simulations investigate how the structure of the zonal-mean flow affects the leading mode of variability. Section 4 concludes with a comparison between the model and observational results.

\section{Observations}

In this section, we investigate the zonal asymmetries of the Northern Annular Mode using observational data. Specifically, we concentrate on the differences between the zonal flow and the leading mode of variability over the Atlantic and Pacific sectors.

\section{a. Data}

Our analysis uses the 40-yr European Centre for Medium-Range Weather Forecasts (ECMWF) ReAnalysis (ERA-40) daily January zonal wind and sea level pressure data from 1970 to 2002. Data are distributed on a $2.5^{\circ} \times 2.5^{\circ}$ latitude by longitude grid with 23 constant pressure levels in the vertical extending from the surface to $1 \mathrm{hPa}$. ECMWF ERA-40 data have been obtained from the ECMWF data server (http://data. ecmwf.int/data/).

\section{b. Hemispheric analysis}

Thompson and Wallace (1998) originally defined the Northern Annular Mode as the leading empirical orthogonal function of winter monthly mean $1000-\mathrm{hPa}$ geopotential height [via sea level pressure (SLP) data] poleward of $20^{\circ} \mathrm{N}$. Wallace (2000) then demonstrated that the leading EOF of the zonal-mean zonal wind is basically the same as the traditional annular mode. Furthermore, Lorenz and Hartmann (2001) showed that the principal component (PC) times series associated with the leading mode of the tropospheric zonal-mean zonal wind in the latitude-height plane matches very well with the PC time series of the vertical-average (from 1000 to $100 \mathrm{hPa}$ ) zonal-mean zonal wind. Figure 1 shows the leading EOF of January vertical-average zonal-mean zonal wind along with the time-mean

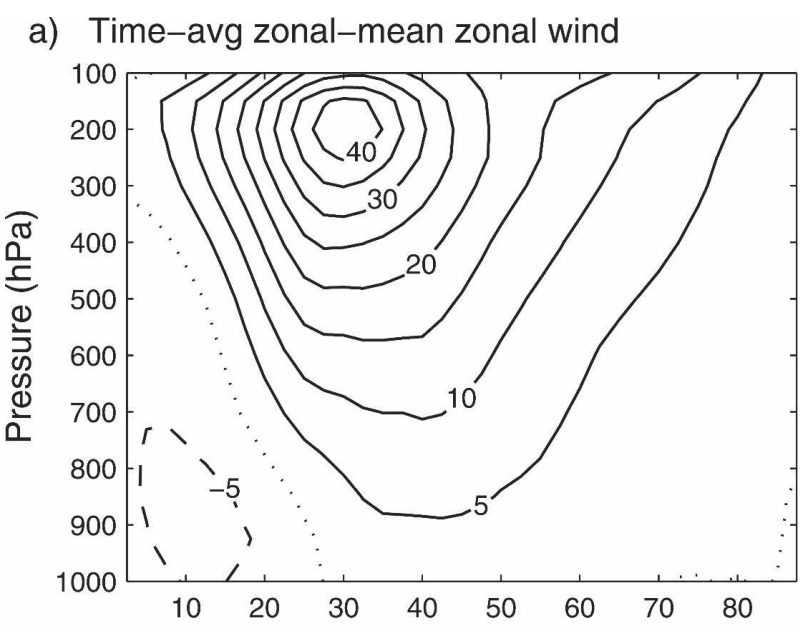

b) Zonal-mean zonal wind regressed on PC1

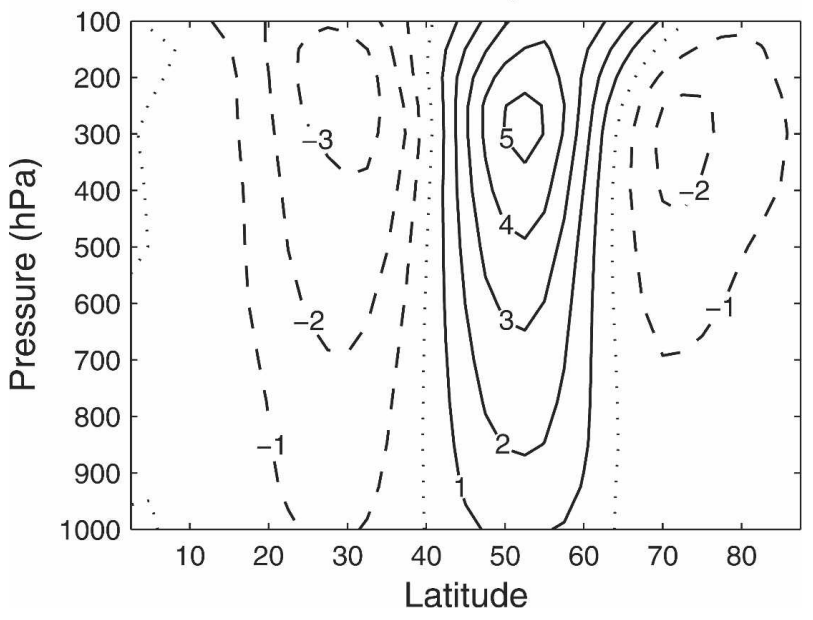

FIG. 1. Time mean and leading EOF of hemispheric zonal-mean zonal wind.

zonal-mean zonal wind. The EOF is shown by regressing zonal-mean zonal wind anomalies onto the standardized PC time series of the vertical-average zonalmean zonal wind, $\langle\bar{u}\rangle$. The zonal-mean zonal wind anomalies are weighted to account for the decrease of area toward the pole (North et al. 1982b). To facilitate comparisons with our model results, we will use 1200 UTC daily instead of monthly mean observational data. The leading EOF explains $36 \%$ of the variance and is unique according to the North et al. (1982a) test. [All leading EOFs shown within this paper pass the North et al. (1982a) criterion for uniqueness at the 95\% level.]

The dominant feature of the leading EOF shown in Fig. 1 is the familiar dipole pattern centered on the latitude of the eddy-driven jet. [Although the strongest zonal wind values occur in the subtropical jet at $200 \mathrm{hPa}$ and $30^{\circ} \mathrm{N}$, the surface westerly wind maximum marks the location of the eddy-driven jet (Lorenz and Hart- 
mann 2003).] Thus, the leading EOF of the hemispheric zonal-mean zonal wind describes north/south shifting in the position of the eddy-driven jet. A weaker third center of action is apparent at high latitudes, centered at $72^{\circ} \mathrm{N}$, and is not seen when using monthly mean data. Despite this difference, the dominant feature of the leading EOF and its association with the time-mean flow remains the same whether we use monthly mean or daily data.

\section{c. Sectoral analysis}

Next we compute the leading mode of variability over the Atlantic and Pacific sectors individually. The Atlantic and Pacific sectors are defined according to Ambaum et al. (2001). The Atlantic sector extends from $300^{\circ} \mathrm{E}$ to $0^{\circ}$, and the Pacific sector spans from $150^{\circ}$ to $240^{\circ} \mathrm{E}$. The results presented below remain valid for slightly altered sector definitions.

Our analysis focuses only on the difference of the time-mean zonal-mean zonal flow and its variability within each sector; that is, we assume that the zonal flow is zonally symmetric within each sector. Thus, the effects of stationary waves, which force zonal variations in the time-mean flow, are neglected. Despite the expected importance of stationary waves, the results demonstrate that the regional zonal-mean flow paradigm can successfully explain observed differences in the variability over the Atlantic and Pacific sectors.

The January-mean Atlantic sector zonal-mean zonal wind, shown in Fig. 2, exhibits a two jet structure in the troposphere. The distinction between the subtropical and eddy-driven jets is very clear, with the eddy-driven jet centered at $47^{\circ} \mathrm{N}$. Figure 2 also displays the leading EOF of the Atlantic sector $\langle\bar{u}\rangle$ which explains $41 \%$ of the variance. A dipole pattern centered on the eddydriven jet dominates the leading EOF. Thus the structure of the first EOF of the Atlantic sector zonal-mean zonal wind compares well with the NAM, which describes north/south variability in the position of the eddy-driven jet. Although the time-mean flow averaged over the Atlantic sector differs from the hemispheric mean, the relationship between the time-mean wind and the leading EOF remains the same.

Figure 3 demonstrates that a single jet dominates the time-mean tropospheric zonal-mean zonal wind averaged over the Pacific sector during January. Unlike the Atlantic sector, the subtropical and eddy-driven jets are very hard to distinguish. The leading Pacific sector EOF, also shown in Fig. 3, explains $42 \%$ of the variance. The leading EOF exhibits a dipole structure centered at $40^{\circ} \mathrm{N}$. However, the latitude of the eddy-driven jet, as defined by the surface westerly wind maximum, is at $35^{\circ} \mathrm{N}$. Thus the leading EOF does not purely de- a) Time-avg zonal-mean zonal wind

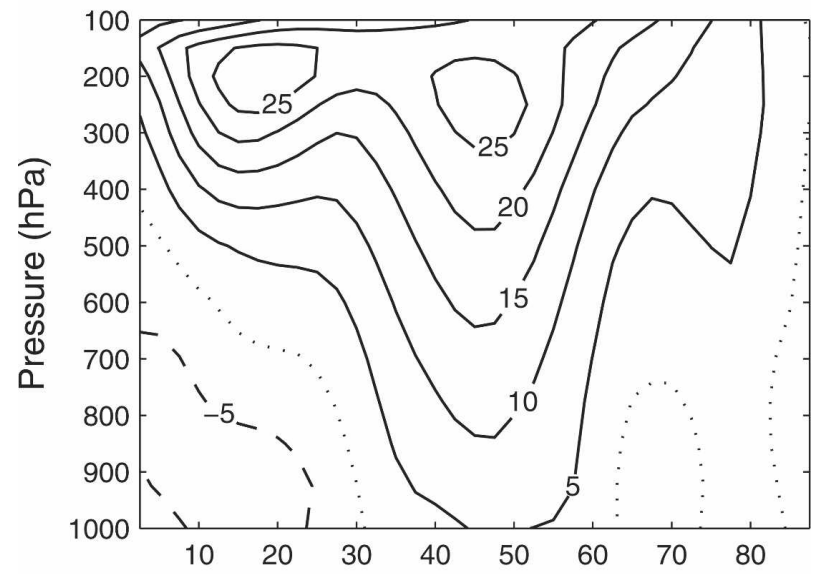

b) Zonal-mean zonal wind regressed on PC1

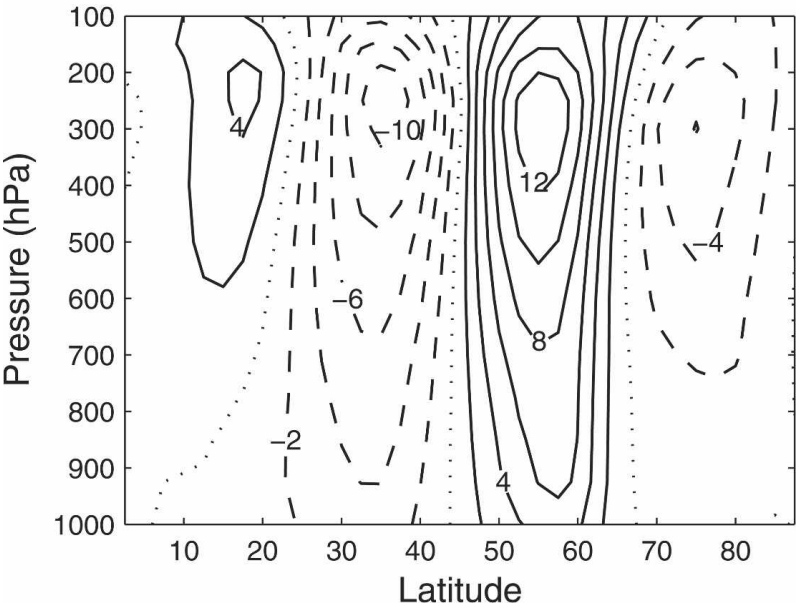

FIG. 2. Time mean and leading EOF of Atlantic sector zonal-mean zonal wind.

scribe north/south shifting of the eddy-driven jet. Instead, much of the variability of the leading EOF appears to be associated with a strengthening and weakening of the upper-level jet at $200 \mathrm{hPa}$. Schubert and Park (1991) reported similar results for the leading EOF of the 20-70-day bandpassed zonally varying zonal wind over the Pacific sector. They found that the first EOF of zonal wind is associated with pulsing in the strength of the westerly jet and also a lengthening and shortening of the zonal extent of the jet. This relationship between the leading EOF and the time-mean flow in the Pacific sector differs from that observed for the hemispheric zonal-mean or the Atlantic sector zonalmean flow.

\section{d. Comparison and discussion}

In the Atlantic sector, the node of the leading EOF dipole is centered on the surface westerly wind maxi- 
a) Time-avg zonal-mean zonal wind

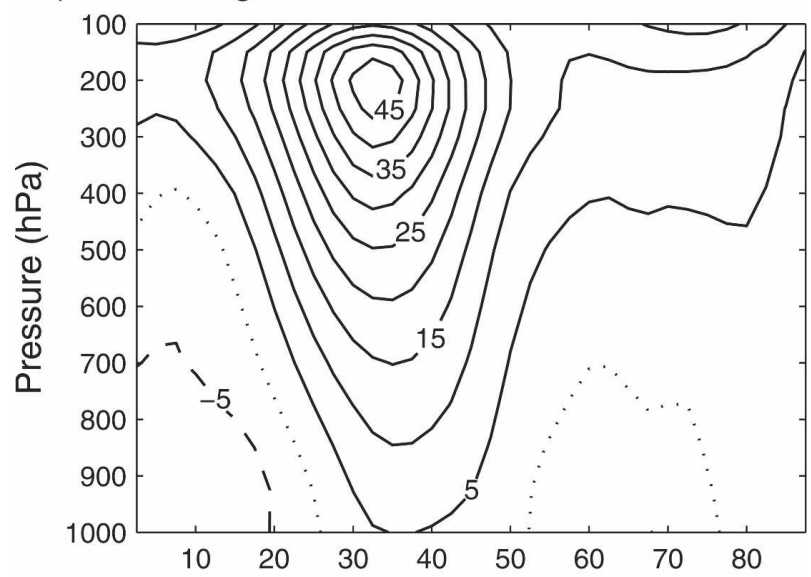

b) Zonal-mean zonal wind regressed on PC1

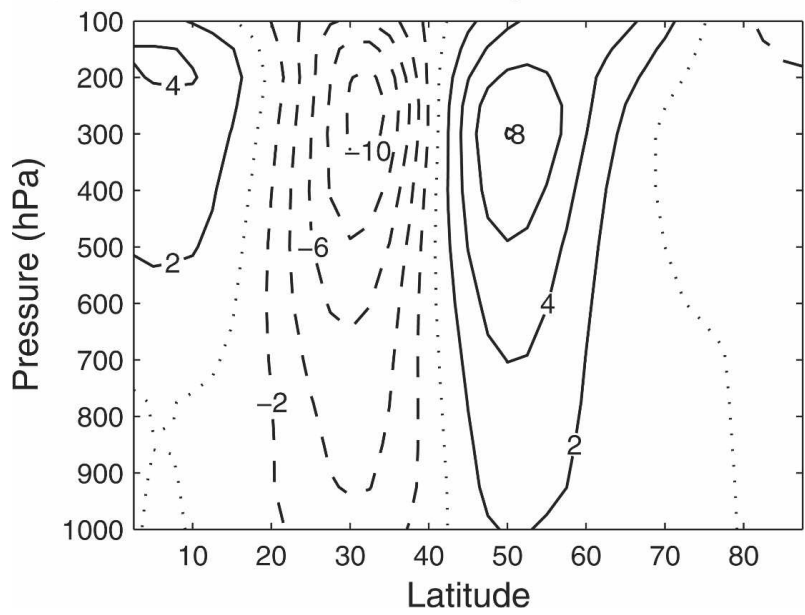

FIG. 3. As in Fig. 2, but for the Pacific sector.

mum, that is, the eddy-driven jet. The situation is altered for the Pacific sector, where the node of the first EOF lies north of the surface westerly wind maximum. Thus, the relationship between the leading EOF and sector-averaged zonal flow changes between the Atlantic and Pacific sectors. This is revealed in Fig. 4, which shows a composite analysis of the vertical-average zonal-mean zonal wind for the Atlantic and Pacific sectors. Days when the standardized PC1 time series is greater than 1 (less than -1 ) are averaged together to form the high (low) index state. [We choose the sign of the PC time series and EOFs such that the high (low) index state refers to days when the eddy-driven jet lies north (south) of its time-mean position.] In the Atlantic sector (Fig. 4a) the latitude of the jet maximum shifts from $53^{\circ} \mathrm{N}$ during the high index phase to $37^{\circ} \mathrm{N}$ in the low index phase, but the amplitude of the jet stays nearly constant. Therefore, EOF1 in the Atlantic sector denotes latitudinal shifting of the jet. In the Pacific sec-

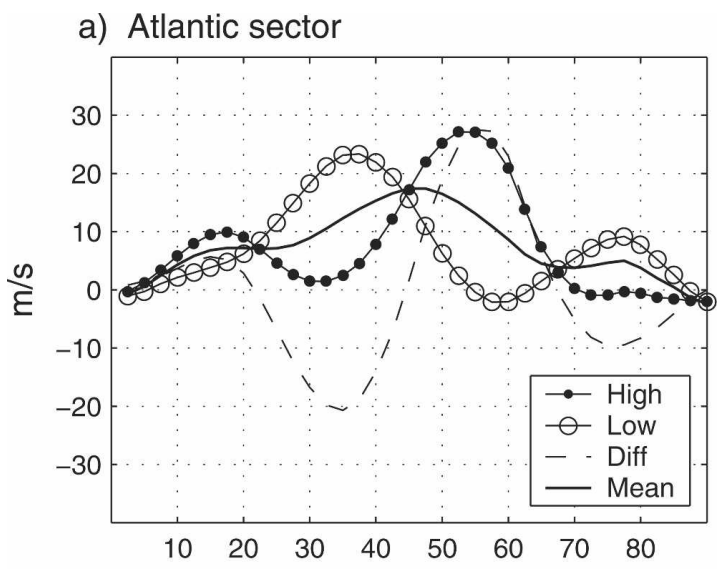

b) Pacific sector

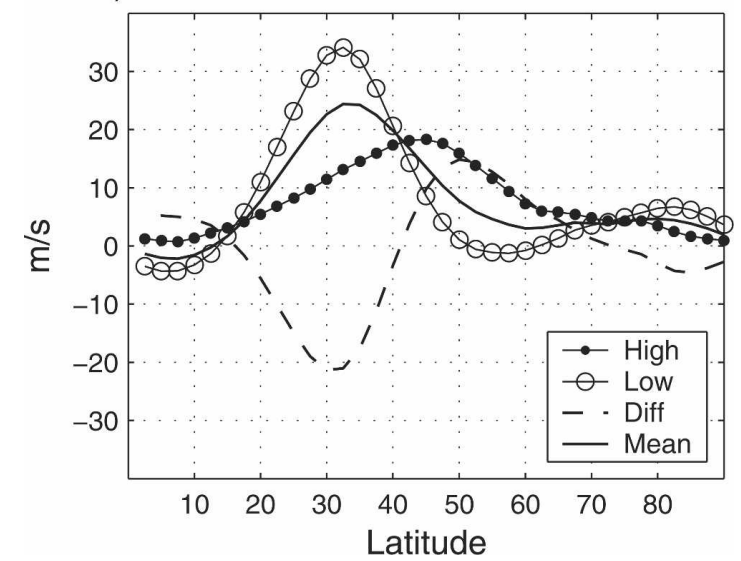

FIG. 4. Atlantic and Pacific sector vertical-average zonal-mean zonal wind composites.

tor, the position of the jet maximum also shifts between the high and low index phases (Fig. 4b). In addition, the amplitude of the Pacific jet changes between the high and low index phases, with the jet becoming much stronger during the low index phase. Thus, EOF1 in the Pacific sector depicts both a shifting and a pulsing of the jet; while in the Atlantic sector, EOF1 describes only a shifting of the jet. Therefore, the variability characterized by the leading EOF of the zonal-mean zonal flow is not the same at all longitudes.

Two different perspectives exist concerning the variability of the Northern Hemisphere (Wallace 2000; Thompson et al. 2002). In the annular mode perspective, the variability of the Northern Hemisphere is seen as being analogous to the variability of the Southern Hemisphere. In the regional perspective, Northern Hemisphere variability results from locally occurring dynamics, and the observed annular structure of the leading mode of variability emerges merely as a statistical artifact.

Ambaum et al. (2001) and Deser (2000) found that 
the temporal correlation between the Atlantic and $\mathrm{Pa}$ cific sectors is very weak. Calculating the temporal correlation between the leading EOFs of the Atlantic and Pacific sectors shown above reveals similarly weak and insignificant values. This is not surprising since the leading mode of variability describes different behavior over the two sectors. These results suggest that a regional perspective may be appropriate for describing Northern Hemisphere variability.

However, Lorenz and Hartmann (2001, 2003) demonstrated that the dynamics that cause the annular mode to be the dominant mode of zonal-mean variability are very similar between the two hemispheres. This result strongly supports the annular mode perspective of Northern Hemisphere variability. Their analysis though, provides no explanation for the reduced amplitude of the NAM over the Pacific sector compared to the Atlantic sector.

In the next section, we develop numerical model simulations designed to investigate the asymmetries of the NAM. The differences in zonal-jet structure over the Atlantic and Pacific sectors motivate the formulation of a hypothesis for the observed differences in the leading mode of variability between the two sectors.

\section{Model experiments}

Results in the previous section reveal that the tropospheric zonal jet structure differs over the Atlantic and Pacific sectors. The differences in the zonal-mean zonal wind can be associated with known differences in the subtropical and eddy-driven jets. In an analysis of subtropical jet strength, Krishnamurti (1961) found that the subtropical jet is stronger and positioned farther north over the Pacific sector compared to the Atlantic sector during Northern Hemisphere winter. Nakamura (1992) investigated the behavior of Northern Hemisphere baroclinic waves during the winter season. He demonstrated that the January-mean storm track (and associated eddy-driven jet) develops farther south in the Pacific sector than the Atlantic. Thus, in a linear sense, the strong Pacific jet results from the superposition of a stronger subtropical jet and a more southerly positioned eddy-driven jet. (Model results shown below demonstrate that linear superposition is a valid approximation.) In the Atlantic sector, the double jet structure of the zonal wind arises from the eddy-driven jet being farther north combined with a weaker subtropical jet. We hypothesize that the different zonal jet structures lead to the observed differences in the leading mode of variability over the Atlantic and Pacific sectors.

To test this hypothesis, we perform a set of numerical simulations using a simple GCM. The model runs are designed to investigate how the leading mode of variability changes with respect to both the position of the eddy-driven jet and the strength of the subtropical jet. These numerical experiments enable us to examine separately the two main differences in zonal jet structure between the Atlantic and Pacific sectors.

\section{a. Model description}

The GCM used in this study solves the dry, hydrostatic primitive equations on a sphere. Saravanan (1992) originally developed the model, and David A. Ortland later converted the model to sigma coordinates. Model resolution is T42 with 40 levels evenly spaced in log pressure extending from the surface to approximately $70 \mathrm{~km}$. A scale-selective $\nabla^{8}$ diffusion operator damps the smallest horizontal scales in the model. Surface friction is applied in the lowest model layer, and a sponge layer exists above $50 \mathrm{~km}$ to eliminate spurious reflections from the top boundary. Damping in the sponge layer is applied to the momentum equations using the following coefficient:

$$
\gamma(z)=0.25 \times\left[1+\tanh \left(\frac{z-z_{\mathrm{sp}}}{5}\right)\right] \mathrm{day}^{-1},
$$

where $z_{\mathrm{sp}}=63 \mathrm{~km}$. The model contains a flat bottom boundary; thus, the effects of stationary waves are not included in our simulations.

Forcing in the model is applied via Newtonian relaxation of temperature to a prescribed zonally symmetric radiative equilibrium temperature field using a heightdependent Newtonian cooling coefficient:

$$
\alpha(z)=0.05+0.2 \exp \left[-\left(\frac{z-50}{10}\right)^{2}\right] \mathrm{day}^{-1},
$$

where $z$ is the height in kilometers. Thus, the radiative damping time is 20 days in the troposphere and decreases to 4 days at $50 \mathrm{~km}$ in the stratosphere.

The radiative equilibrium temperature field, $T_{\text {eq }}$, is defined as

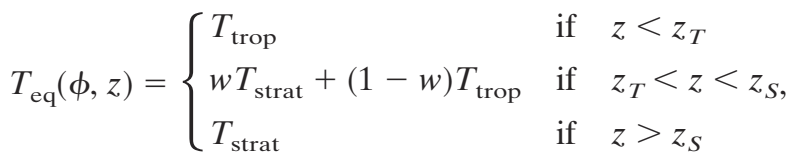

where $z_{T}=6 \mathrm{~km}, z_{S}=17.5 \mathrm{~km}$, and

$$
w=\frac{z-z_{T}}{z_{S}-z_{T}} .
$$

Here $T_{\text {trop }}$ is defined to be equal to the initial zonalmean temperature field, $T_{0}$, and $T_{\text {strat }}$ is set equal to 
January radiative equilibrium temperature values (Shine 1987). The initial temperature field, $T_{0}$, is defined to be in geostrophic balance with the initial zonal-mean zonal wind, $u_{0}$. The initial zonal wind field is analytically defined using the equations in Scinocca and Haynes (1998); see appendix A. These equations allow the latitude of the tropospheric jet maximum to be specified without affecting the rest of the profile.

As mentioned above, the radiative equilibrium temperature profile, $T_{\text {eq }}$, equals $T_{0}$ in the troposphere. Thus, by moving the position of the tropospheric jet maximum in the initial zonal-mean zonal wind profile, $\phi_{2}$, we also change the latitude of the maximum meridional temperature gradient of $T_{\mathrm{eq}}$ via the thermal wind relation. The latitude of the maximum meridional temperature gradient of $T_{\mathrm{eq}}$ defines the position of the extratropical baroclinic zone. The time-mean position of the eddy-driven jet will exist at the latitude of the time-mean baroclinicity maximum. Therefore, the latitude of the tropospheric jet maximum, $\phi_{2}$, determines the center of the extratropical baroclinic zone and, in turn, the region within which the time-mean eddydriven jet will be located. Shifting $\phi_{2}$ north or south will cause a corresponding shift in the position of the timemean eddy-driven jet (all other parameters being equal).

Additional forcing is applied in the model using a zonally symmetric tropical heat source. The heating is prescribed as follows:

$$
Q(\phi, z)=Q_{0} \exp \left[-\left(\frac{\phi-\phi_{0}}{\phi_{w}}\right)^{2}\right] \sin \left(\frac{\pi z}{z_{0}}\right),
$$

for $z \leq z_{0}$. Parameters are chosen to represent the heating associated with tropical convection in the intertropical convergence zone (ITCZ), that is, a tropospheric heat source centered south of the equator: $Q_{0}=2.0 \mathrm{~K}$ day $^{-1}, \phi_{0}=-6^{\circ}, \phi_{w}=4.5^{\circ}$, and $z_{0}=12 \mathrm{~km}$. The amplitude of the heat source asymptotically increases to $Q_{0}$ over the first 30 days and then remains constant. This heat source drives a Hadley cell that typifies Northern Hemisphere winter conditions. Running the model with only the heat source forcing causes a Hadley circulation to develop that drives a subtropical jet of $25 \mathrm{~m} \mathrm{~s}^{-1}$ at $25^{\circ} \mathrm{N}$.

In the winter hemisphere upper stratosphere and mesosphere, the meridional gradient of January radiative equilibrium temperatures is very large. If these temperatures are achieved, gradient wind balance implies a polar vortex with westerly winds in excess of $200 \mathrm{~m} \mathrm{~s}^{-1}$. Such strong winds are not observed in the real atmosphere because gravity waves deposit easterly momentum in the mesosphere (Holton 1983). To incorporate the effect of gravity waves in our model, we apply a constant flow-independent force per unit mass on the zonal-mean zonal wind. This zonal-mean zonal wind tendency is designed to provide the drag needed to reproduce the observed distribution of zonal-mean zonal winds in the upper stratosphere and mesosphere in the model. Appendix B contains details on the calculation of the zonal-mean zonal wind tendency.

The model is integrated forward using a Robert filtered semi-implicit leapfrog scheme with a time step of $15 \mathrm{~min}$. To initiate variability in the model, we add white noise to the day zero vorticity, divergence, and temperature fields. The initial vorticity and divergence fields are calculated from the prescribed initial zonalmean zonal wind, $u_{0}$. Model runs are integrated for 2500 days. The first 500 days of model data are not used in the analysis, allowing time for model spinup. All model parameters are held constant in time; that is, the model is run under perpetual January-mean conditions.

\section{b. Results}

In this section, we show results from three model runs using two different initial zonal-mean zonal wind profiles. In the first run, denoted J45, the initial zonalmean zonal wind, $u_{0}$, is defined using the equations in appendix A with $\phi_{2}=45^{\circ} \mathrm{N}$ and $U_{0 t}=45 \mathrm{~m} \mathrm{~s}^{-1}$. (As mentioned above, the latitude of the $u_{0}$ jet maximum, $\phi_{2}$, corresponds to the latitude of the maximum meridional temperature gradient of $T_{\mathrm{eq}}$ and, in turn, to the position of the eddy-driven jet.) The two additional runs, denoted $\mathrm{J} 35$ and $\mathrm{J} 35-4 \mathrm{~K}$, use $\phi_{2}=35^{\circ} \mathrm{N}$ and $U_{0 t}=55 \mathrm{~m} \mathrm{~s}^{-1}$ to define $u_{0}$. The magnitude of the jet maximum, $U_{0 t}$, increases in the $\mathrm{J} 35$ and $\mathrm{J} 35-4 \mathrm{~K}$ model runs so that the meridional gradient of $T_{\text {eq }}$ remains constant among the runs. (Since the Coriolis parameter decreases toward the equator, the thermal wind relation requires that the vertical gradient of $u$ must increase to keep the meridional gradient of temperature constant.) Because the meridional gradient of $T_{\text {eq }}$ remains constant among the model runs, the Eady wave growth rate for the most unstable mode,

$$
0.31\left(g / \theta_{0}\right)\left|\bar{\theta}_{y}\right| / N
$$

also remains constant (Eady 1949).

The J35 and J35-4K runs differ only in the strength of the tropical heating. The tropical heat source in the J35-4K run is defined using Eq. (4) with $Q_{0}=4.0 \mathrm{~K}$ day $^{-1}$, that is, double the value used in the J35 and J45 model runs. Thus, in the J45 model run, the eddydriven and subtropical jets will be well separated. While in the J35-4K model run, the two jets will be very close together. 
a) Time-avg zonal-mean zonal wind

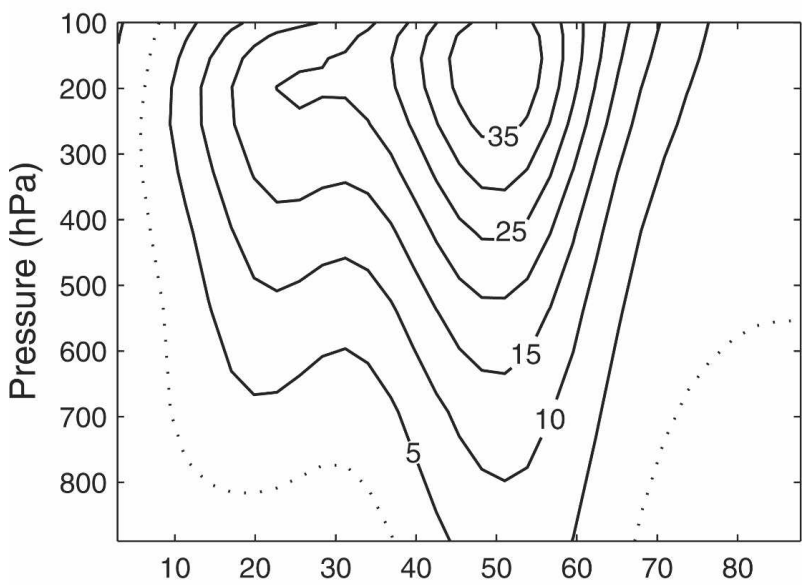

b) Zonal-mean zonal wind regressed on PC1

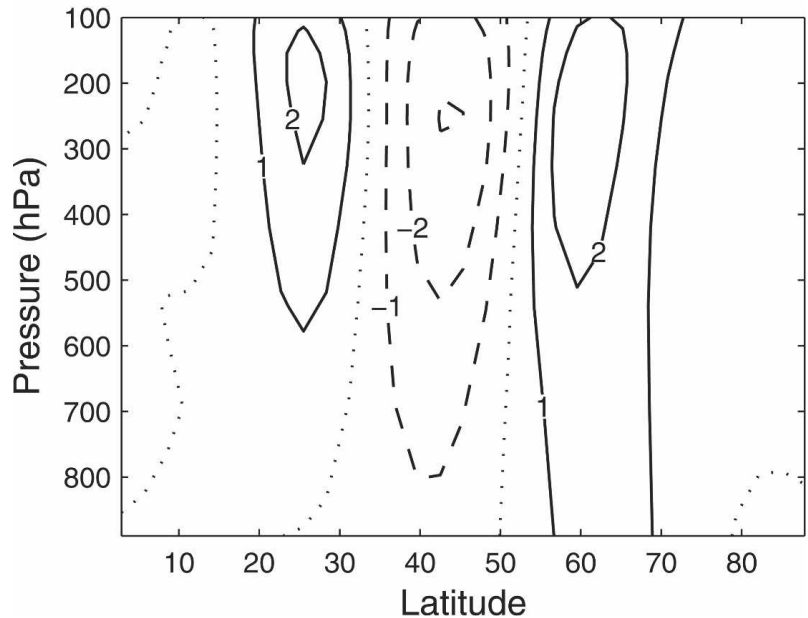

FIG. 5. Time mean and leading EOF of J45 zonal-mean zonal wind.

\section{1) LEADING MODE OF VARIABILITY}

Figure 5 shows the time-mean zonal-mean zonal wind of the J45 model run along with the first EOF of the zonal flow. As in the previous section, EOFs are shown by regressing zonal-mean zonal wind anomalies onto the standardized PC time series of the verticalaverage zonal-mean zonal wind. Examining the timemean flow, we see a nearly two jet structure of the zonal wind with a subtropical jet at $25^{\circ} \mathrm{N}$ and an eddy-driven jet at $50^{\circ} \mathrm{N}$. The time-mean eddy-driven jet is weaker and shifted slightly north compared to the initial zonalmean zonal wind profile due to the eddies that develop in the model.

The leading EOF for the J45 model run, shown in Fig. 5b, consists of a dipole pattern centered on the axis of the eddy-driven jet. Thus, the first EOF describes latitudinal shifting of the eddy-driven jet. An additional a) Time-avg zonal-mean zonal wind

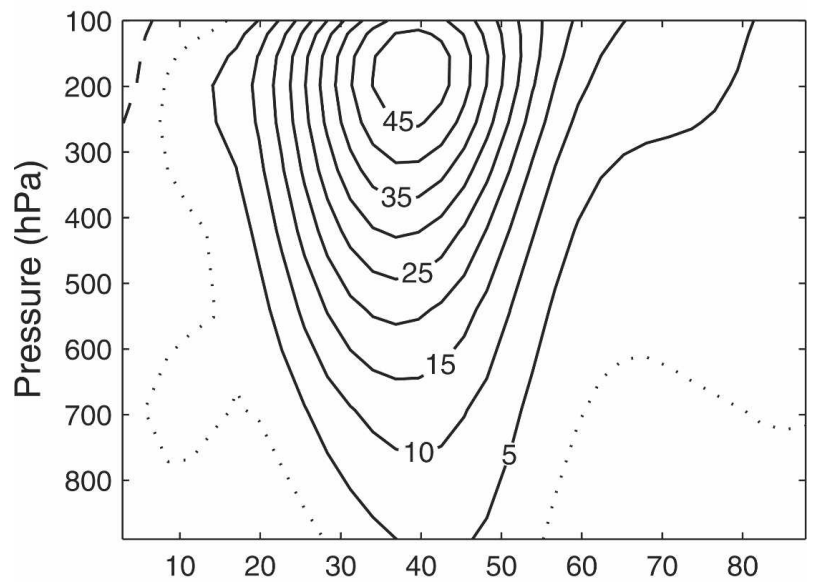

b) Zonal-mean zonal wind regressed on PC1

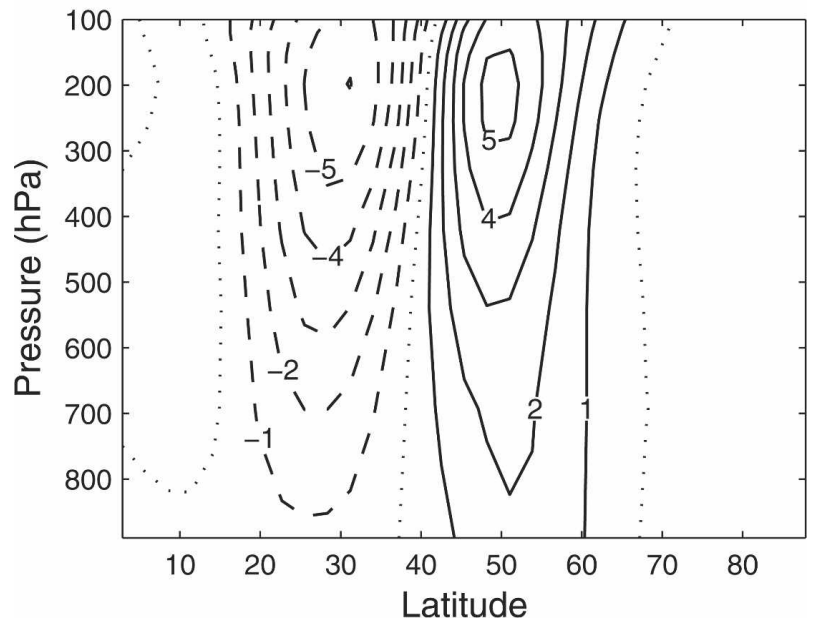

FIG. 6. As in Fig. 5 but for J35.

center of action exists near the axis of the subtropical jet.

Figure 6 contains the time-mean zonal-mean zonal wind and leading EOF of the J35 model run. The timemean wind consists of a single jet maximum. The eddydriven jet, based on the surface westerly wind maximum, is centered near $40^{\circ} \mathrm{N}$. The leading EOF is a dipole pattern centered on the axis of the eddy-driven jet; therefore, the first EOF describes north/south shifting of the eddy-driven jet position. Comparing Figs. 5 and 6 , we see that the relationship between the timemean flow and the leading EOFs is similar in the J35 and $\mathrm{J} 45$ model runs.

Figure 7 reveals that the relationship between the leading EOF and the mean flow changes for the J35-4K integration. The J35-4K time-mean zonal-mean zonal wind is dominated by a single, sharp jet centered at $30^{\circ} \mathrm{N}$, and the eddy-driven jet exists near $35^{\circ} \mathrm{N}$. The 
a) Time-avg zonal-mean zonal wind

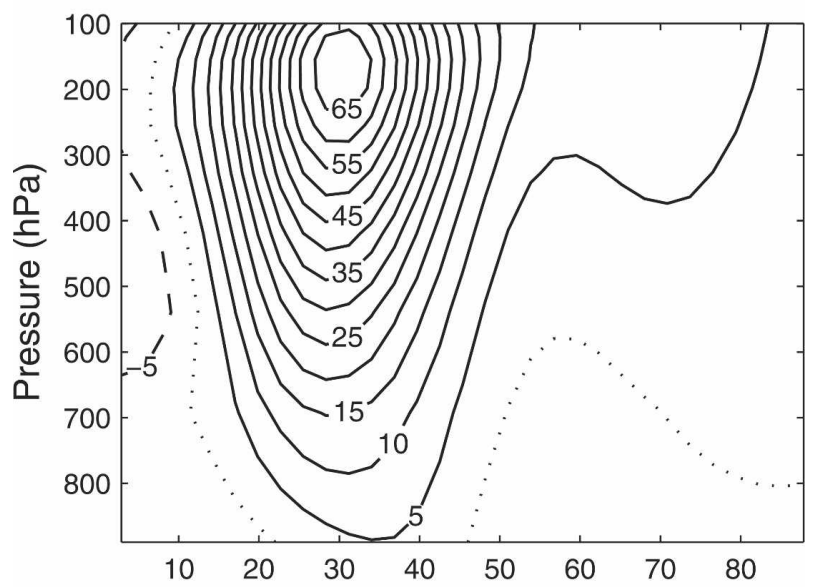

b) Zonal-mean zonal wind regressed on PC1

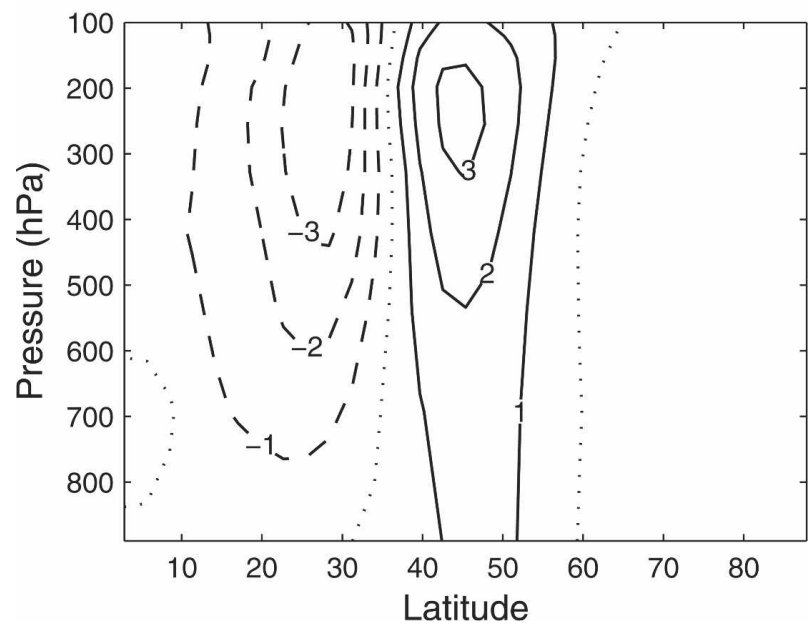

FIG. 7. As in Fig. 5, but for J35-4K.

leading EOF is centered on the axis of the eddy-driven jet but, in contrast to the J45 and J35 model runs, the eddy-driven jet in the $\mathrm{J} 35-4 \mathrm{~K}$ case is not located at the same latitude as the upper-tropospheric jet maximum. In particular, the negative lobe of the leading EOF is collocated with the upper-tropospheric jet maximum at $30^{\circ} \mathrm{N}$. Therefore, while the leading EOF denotes a meridional shifting of the eddy-driven jet, it also represents pulsing of the upper-level jet.

To better illustrate the differences among the leading mode of variability of the three model runs, we perform a composite analysis of the vertical-average zonal-mean zonal wind. Days when the standardized PC time series is greater than 1 (less than -1 ) are averaged together to form the high (low) index state. [As before, the sign of the PC time series and EOFs is chosen such that the high (low) index state refers to days when the eddydriven jet resides north (south) of its time-mean posi-

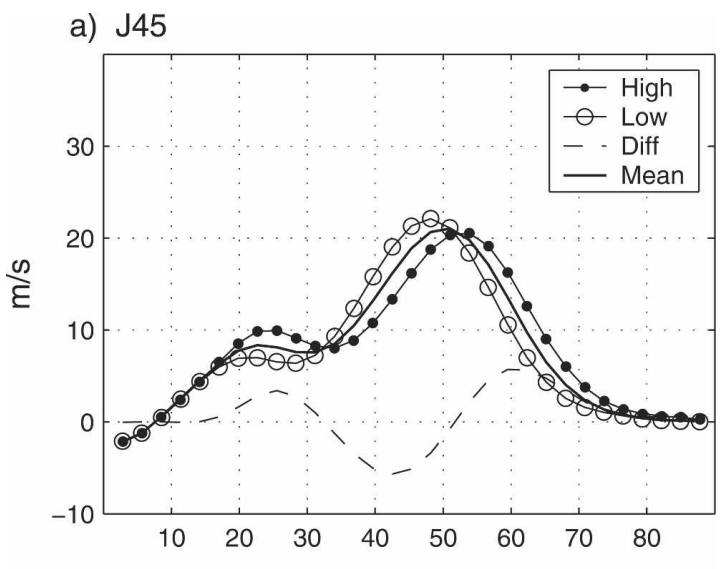

b) J35

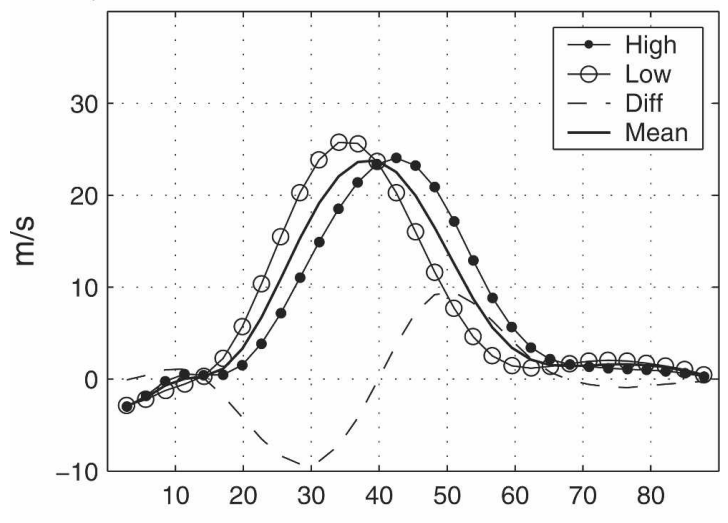

c) $\mathrm{J} 35-4 \mathrm{~K}$

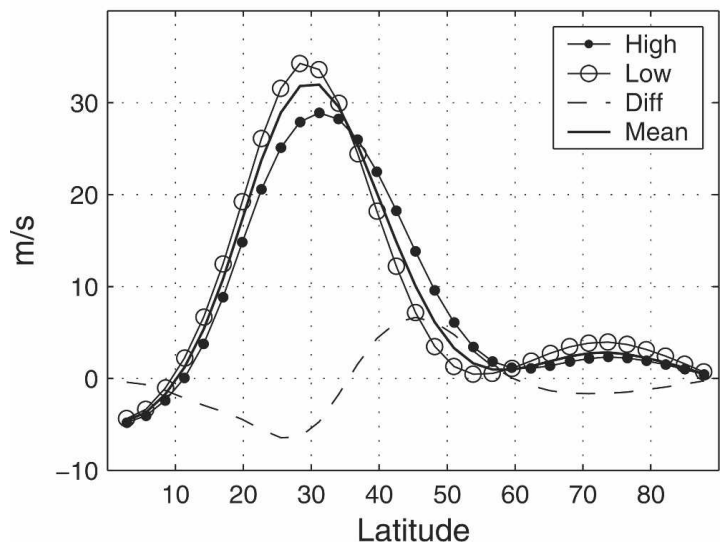

FIG. 8. J45, J35, and J35-4K vertical-average zonal-mean zonal wind composites.

tion.] Figure 8 shows the high, low, difference (high low), and mean states of the vertical-average zonalmean zonal wind for the three model runs.

For the J45 run, the shifting of the eddy-driven jet, located at $50^{\circ} \mathrm{N}$, accounts for the largest difference between the high and low index states. Similarly in the J35 model run (Fig. 8b), the difference between the high 
and low index states is dominated by latitudinal shifting of the eddy-driven jet. However, in the J35-4K run, changes in the strength of the jet account for the majority of the difference between the high and low index states. The latitude of the jet also shifts back and forth between the high and low index states in the J35-4K model run, but the change is less than in either the J45 or J35 model runs. Comparing the high index and low index phases of the J35-4K model run, we see that the jet is stronger, sharper, and displaced slightly equatorward during the low index phase.

In summary, as the eddy-driven jet moves equatorward and the subtropical jet strength increases, the time-mean flow transitions from a nearly two jet structure to a single, strong jet. [Son and Lee (2005) reported a qualitatively similar shift in the time-mean zonal jet structure in their study, which investigated the response of the zonal jet stricture to changes in tropical heating and high-latitude cooling.] As the zonal jet structure changes, the leading mode of variability changes from describing solely the position of the eddydriven jet in the $\mathrm{J} 45$ case to describing a mixture of pulsing and shifting of the combined (eddy-driven and subtropical) jet in the J35-4K model run. In the next section, we attempt to find an explanation for this change in the leading mode of variability by examining the response of the eddies to the zonal wind anomalies of EOF1.

\section{2) EdDy FEEDBACK STRENGTH AND DYNAMICS}

Lorenz and Hartmann (2003) demonstrated that a positive feedback exists between the eddy momentum fluxes and the zonal-mean zonal wind anomalies associated with the leading modes of variability in the Northern Hemisphere. This feedback is strongest for the leading mode of variability and is responsible for the leading mode's increased persistence and variance over the other modes. To calculate the strength of the feedback, we first compute an eddy forcing time series using the vertical-average zonal momentum equation:

$$
\frac{\partial\langle\bar{u}\rangle}{\partial t}=-\frac{1}{a \cos ^{2} \phi}\left(\frac{\partial \cos ^{2} \phi\left\langle\overline{u^{\prime} v^{\prime}}\right\rangle}{\partial \phi}\right)-F .
$$

The vertical-average zonal-mean zonal wind is forced only by the eddy-momentum flux convergence and residual forcing, $F$, which is dominated by friction. (Mountain torque is not included because the model does not have any topography.) We calculate the eddy forcing time series by projecting the leading EOF pattern of $\langle\bar{u}\rangle$ onto the eddy momentum flux convergence anomalies. The strength of the feedback is then evalu- a) $\mathrm{J} 45$

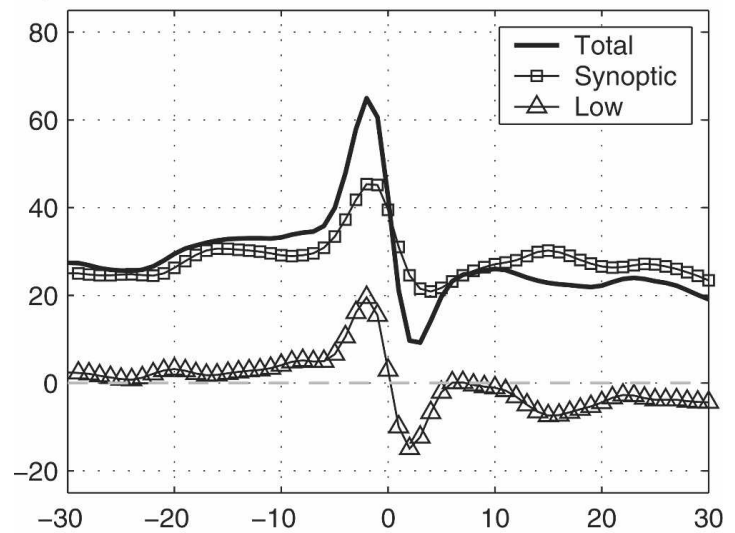

b) J35

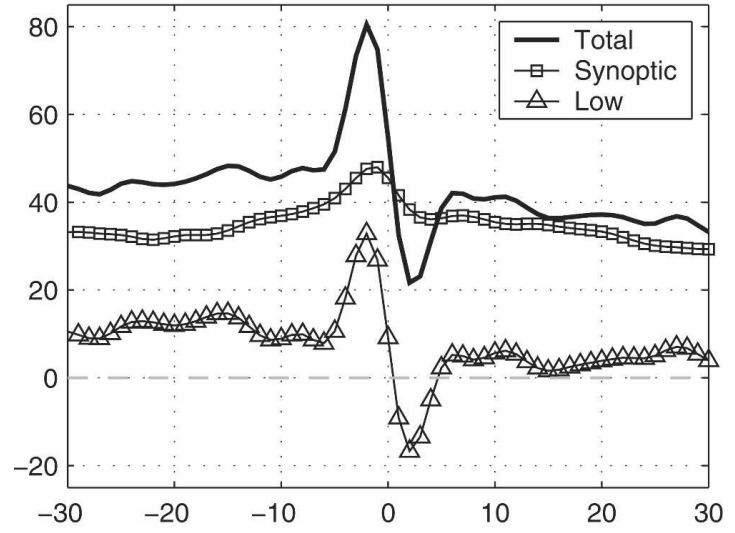

c) J35-4K

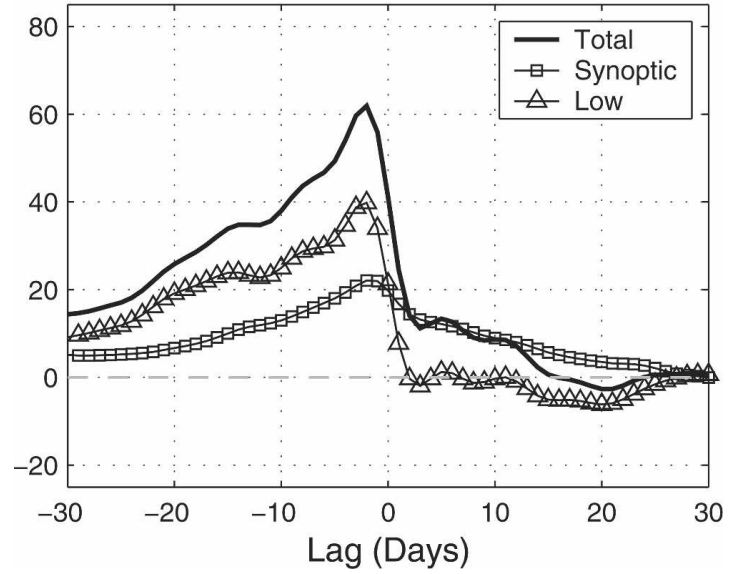

FIG. 9. J45, J35, and J35-4K cross-covariance between leading PC time series and eddy forcing.

ated by taking the cross-covariance between the leading PC time series of $\langle\bar{u}\rangle$ and its eddy forcing time series.

The results of the cross-covariance analysis are shown in Fig. 9 for all three model runs. In addition to showing the total eddy response, Fig. 9 also shows the 
contribution from the time-filtered synoptic and lowfrequency eddies. [The high-frequency (synoptic) eddies are defined using a high-pass fourth-order Butterworth filter with a cutoff of 15 days. The low-frequency eddies are simply the remainder after removing the high-frequency eddies.] The covariance is largest for all model runs at small negative lag, when the eddies lead the zonal wind, because the eddies force the zonal wind anomalies [see Eq. (5)]. As discussed in Lorenz and Hartmann (2003), though, evidence of the feedback is seen at large positive lags beyond the lifetime of an individual eddy. This argument assumes that without the low-frequency variability of the zonal-mean flow, the eddies would have no long-term memory.

Examining Fig. 9 at large positive lags, both J45 and J35 model runs exhibit positive covariance values. In the J35-4K model run, the covariance values steadily decrease with increasing lag, which implies that the feedback mechanism is weaker for the J35-4K model run. In the real atmosphere, covariance values are strongest for the leading EOF, which purely describes meridional displacement of the eddy-driven jet. Since the leading EOF of the J35-4K model run describes both pulsing and shifting of the jet, it was expected that the feedback strength would be weaker for the J35-4K model run compared to the J35 and J45 runs. [Lorenz and Hartmann $(2001,2003)$ showed that meridional displacements of the jet generate positive feedbacks that add persistence to anomalies, whereas strengthening and narrowing of the jet does not.] Figure 9 confirms this.

To determine whether the eddies reinforce the zonal wind anomalies, we calculate the lag regression of the vertical-average eddy forcing, that is, the eddymomentum flux convergence. The regressions are averaged over positive lags from day 8 to 30 , which allows us to isolate the part of the eddy forcing that responds to the zonal wind anomalies from the initial surge of eddy forcing that creates the zonal wind anomalies (Lorenz and Hartmann 2003). Since the synoptic waves dominate the eddy response to the zonal wind anomalies (Fig. 9), our analysis of the eddy response focuses solely on the synoptic eddies.

Figure 10 shows the vertical-average synoptic eddy forcing along with the leading EOF (shown as the regression of $\langle\bar{u}\rangle$ anomalies onto the leading PC time series) for each model run. The synoptic eddy forcing matches well with the leading EOF in the J45 model run. Thus, the synoptic eddies reinforce the zonal wind anomalies associated with the leading EOF. A similar situation exists in the J35 model run, although the synoptic eddy forcing does not project as well onto the southern branch of the leading EOF. The eddy forcing

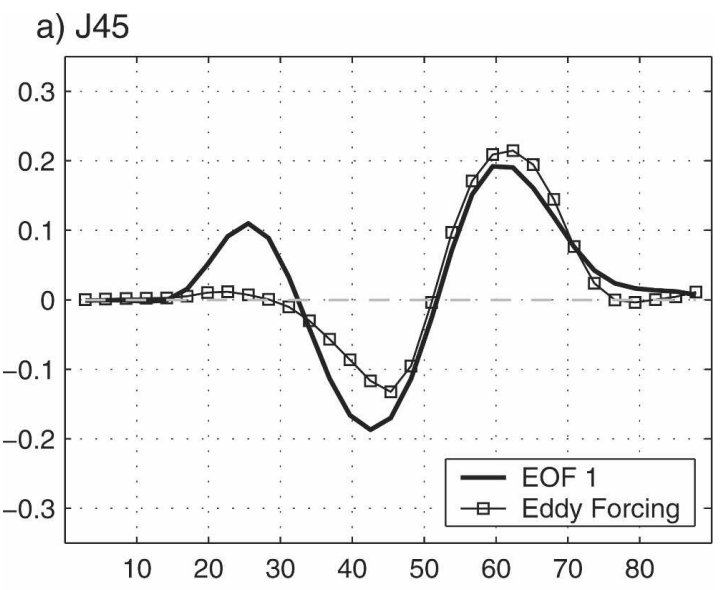

b) J35

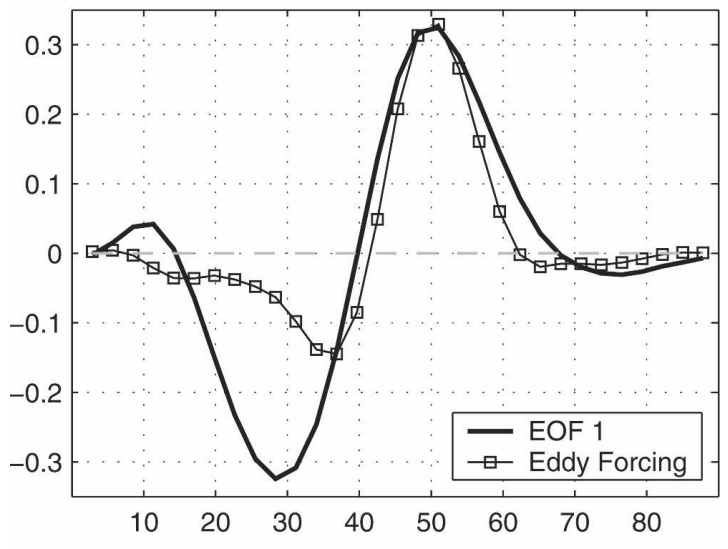

c) J35-4K

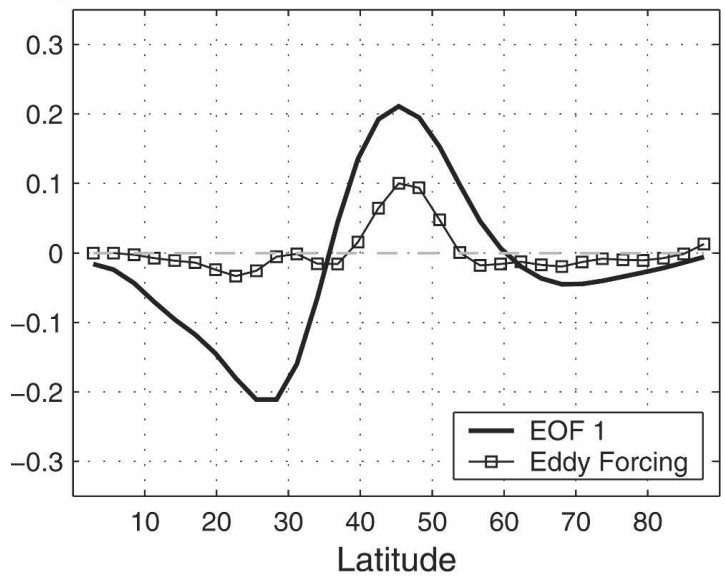

FIG. 10. J45, J35, and J35-4K lag regression of the vertical-average synoptic eddy forcing $\left(\mathrm{m} \mathrm{s}^{-1} \mathrm{day}^{-1}\right)$.

is much weaker in the $\mathrm{J} 35-4 \mathrm{~K}$ model run and projects poorly onto the leading EOF. In particular, the eddy forcing is nearly zero south of the EOF1 node, that is, during the low index phase. Figure 10c suggests that the 


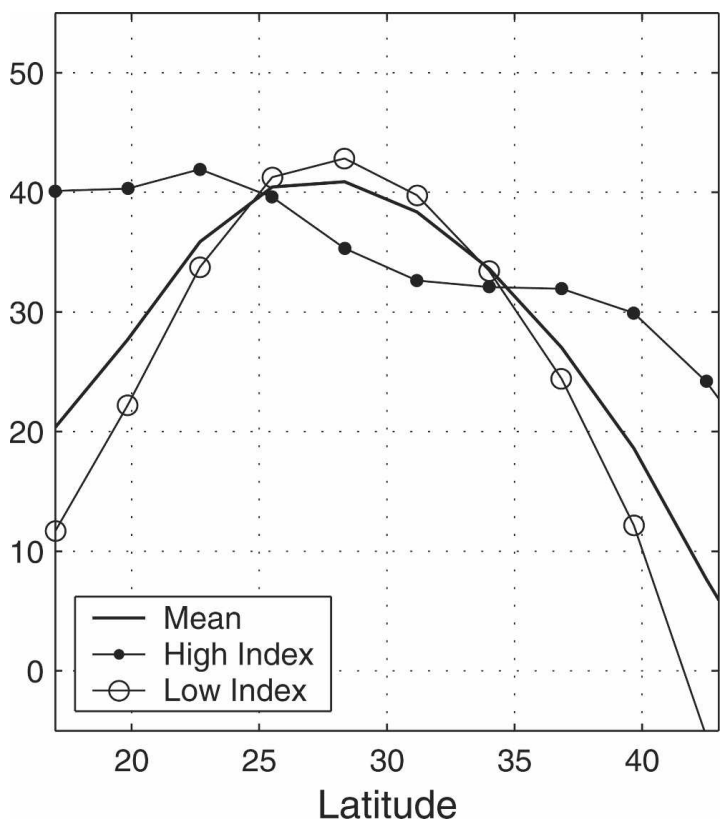

FIG. 11. J35-4K index of refraction composites.

eddy response to the zonal wind anomalies of EOF1 becomes weaker when the subtropical jet is very strong, especially during the low index phase of the EOF. An explanation for this behavior is found by examining the index of refraction.

The index of refraction is calculated using the following equation:

$$
n^{2}=\frac{\frac{\partial \bar{q}}{\partial \phi}}{\bar{u}-c \cos \phi / \cos \phi_{0}}-\left(\frac{k}{a \cos \phi}\right)^{2}-\left(\frac{f}{2 N H}\right)^{2},
$$

where

$$
\frac{\partial \bar{q}}{\partial \phi}=\frac{2 \Omega}{a} \cos \phi-\frac{1}{a^{2}}\left[\frac{(\bar{u} \cos \phi)_{\phi}}{\cos \phi}\right]_{\phi}-\frac{f^{2}}{\rho_{0}}\left(\rho_{0} \frac{\bar{u}_{z}}{N^{2}}\right)_{z}
$$

[Notation follows Andrews et al. (1987) where $q$ is the potential vorticity, $N$ is the buoyancy frequency, $H$ is the scale height, and $\rho_{0}$ is density.] Waves can propagate within regions of positive refractive index and are evanescent in negative regions. Waves also tend to propagate toward regions with larger positive index of refraction values. The phase speed, $c$, and zonal wavenumber, $k$, used in Eq. (6) are those values that maximize the phase speed/zonal wavenumber covariance spectrum of the eddy kinetic energy at the latitude of the jet core (Randel and Held 1991).

Figure 11 shows the time-mean vertical-average index of refraction along with composite values during the high index and low index of EOF1 for the J35-4K model run. (Zonal wavenumber 5 is dominant with a phase speed of $4 \mathrm{~m} \mathrm{~s}^{-1}$ in the J35-4K model run.) Since the strongest momentum fluxes occur in the upper troposphere, the index of refraction is vertically averaged from 200 to $500 \mathrm{hPa}$. The time-mean index of refraction has higher values within the jet core than on the flanks of the jet. Since waves tend to propagate toward regions of higher refractive index, this implies that waves will be less likely to propagate meridionally away from the source region. Without sufficient meridional propagation of wave activity away from the source region, the westerly momentum fluxes into the source region (the positive feedback) will be very weak and the westerly wind anomalies will not be self-maintaining (Robinson 2000). Thus, the eddy-zonal flow feedback is greatly reduced during the low index of EOF1 in the J35-4K model run. Only during the high index phase of EOF1, when the jet is weaker and broader, does the index of refraction have the opposite curvature, that is, higher refractive index values on the flanks of the jet than in the jet core. Thus, waves are able to propagate meridionally away from the source region, generating momentum fluxes that will maintain the westerly wind anomalies during the high index phase of EOF1. Composites of Eliassen-Palm (EP) vectors during the high index and low index (not shown) correspond well with the index of refraction composites.

Figure 12a provides additional confirmation that the magnitude of the eddy momentum fluxes decreases as the strength of the subtropical jet increases. Figure 12a shows the time-mean eddy momentum flux convergence at $200 \mathrm{hPa}$ for both $\mathrm{J} 35$ and $\mathrm{J} 35-4 \mathrm{~K}$ model runs. The maximum flux convergence is $3.25 \mathrm{~m} \mathrm{~s}^{-1}$ day $^{-1}$ for the $\mathrm{J} 35$ run, but decreases by a third in the $\mathrm{J} 35-4 \mathrm{~K}$ model run.

The change in the time-mean eddy momentum flux convergence could be caused by a decrease in the wave activity near the surface. To investigate this possibility, we compute the eddy heat flux at $890 \mathrm{hPa}$ since the eddy heat flux is proportional to the vertical flux of wave activity (via the Eliassen-Palm relation). Figure $12 \mathrm{~b}$ displays the time-mean eddy heat flux at $890 \mathrm{hPa}$ for both model runs. Increasing the strength of the subtropical jet, via a stronger tropical heat source, causes the latitude of maximum eddy heat flux to shift equatorward. The magnitude of the eddy heat flux, though, does not significantly change. Thus, the eddy heat flux, that is, the vertical flux of wave activity, near the surface remains nearly constant as the subtropical jet strength increases. This supports our argument that the zonal-mean jet structure controls the strength of the positive feedback between the eddies and zonal wind anomalies associated with the leading EOF. 
a) Eddy momentum flux convergence at $200 \mathrm{hPa}$

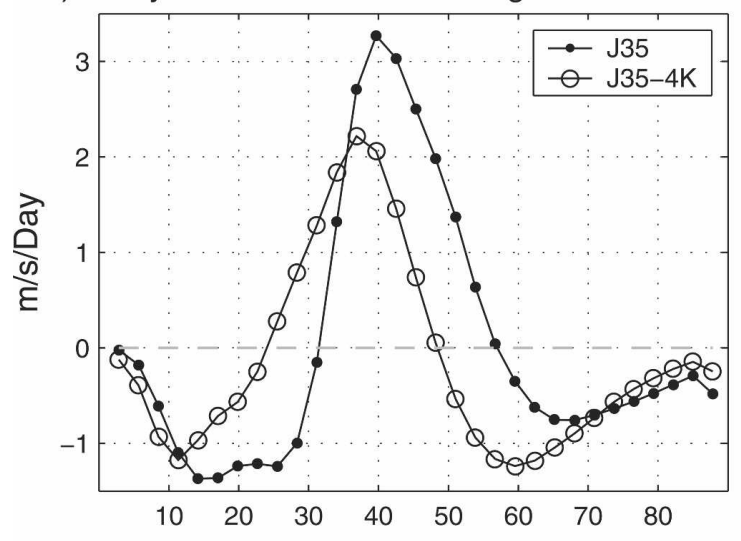

b) Eddy heat flux at $890 \mathrm{hPa}$

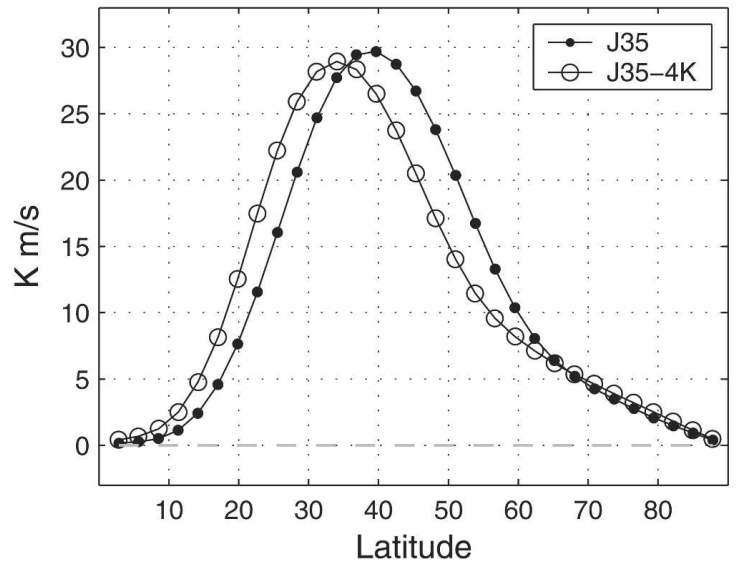

FIG. 12. J35 and J35-4K time-mean eddy fluxes.

In summary, as the distance between the eddy-driven and subtropical jets decreases, the leading mode of variability changes. In the $\mathrm{J} 45$ and $\mathrm{J} 35$ model runs, where the subtropical and eddy-driven jets are well separated, the leading EOF describes shifting in the position of the eddy-driven jet. The synoptic eddies reinforce the zonal wind anomalies associated with the leading EOF in both the J45 and J35 model runs. Increasing the subtropical jet strength in the J35-4K model run, via increased tropical heating, causes the subtropical and eddy-driven jets to be positioned closer together. The leading mode of variability in the J35-4K model run is dominated by pulsing of the jet strength, and the positive feedback between the eddies and zonal flow weakens. The feedback weakens in the J35-4K model run because the increased jet strength reduces meridional wave propagation out of the jet, which then reduces the restoring momentum fluxes. In other words, the strong jet of the J35-4K model run acts as a waveguide whose strength determines whether the eddies will reinforce the zonal wind anomalies or not. This behavior is not seen in either the $\mathrm{J} 35$ or $\mathrm{J} 45$ model runs because 1) the time-mean upper-tropospheric jet is weaker and 2) the wave source region is situated away from the subtropical jet axis. In the J35-4K run the eddy-driven jet, that is, the wave source region, is located very close to the axis of the subtropical jet, which magnifies the importance of the upper-tropospheric jet structure on the eddy feedback process.

These results correspond well with Lee and Kim (2003), who investigated how the strength of the subtropical jet affects the development of the most unstable baroclinic wave in a primitive equation model. In their runs, when the subtropical jet is weak, the waves develop an eddy-driven jet positioned far poleward of the subtropical jet. Thus, a two-jet zonal wind structure is achieved. When Lee and Kim increase the subtropical jet strength, the waves develop on the poleward edge of the subtropical jet, resulting in a single-jet zonal wind structure. In addition, they note that meridional wave propagation decreases as the subtropical jet strength increases. Although we have not investigated the eddy life cycles in our model runs, the results described by Lee and Kim (2003) are consistent with the time-mean statistics presented in the previous sections.

\section{Comparison to observations and conclusions}

In this section we apply the findings of our idealized model experiments to the real atmosphere. The results from the previous section are used to help understand the differences between the leading modes of variability over the Atlantic and Pacific sectors discussed in section 2.

The time-mean zonal flow of the J45 simulation provides a good approximation to the January-mean zonalmean zonal flow over the Atlantic sector because the eddy-driven and subtropical jets are well separated from one another, and a double-jet structure is nearly achieved. The $\mathrm{J} 45$ leading mode of variability describes north/south shifting of the eddy-driven jet, as does the leading mode over the Atlantic sector. The synoptic eddies in the J45 model run positively reinforce the zonal wind anomalies associated with the leading mode.

The time-mean zonal wind of the J35-4K model run is stronger than observed over the Pacific sector, but it does capture the two defining characteristics of the Pacific zonal flow. First, the time-mean position of the January-mean storm track (and associated eddy-driven jet) over the Pacific is near $35^{\circ} \mathrm{N}$ (Nakamura 1992). Second, tropical heating in the Pacific sector exceeds that in the Atlantic sector due to increased convection over the West Pacific warm pool, which drives a stronger subtropical jet. In addition, the leading mode of 
variability of the Pacific sector is qualitatively consistent with the J35-4K model run. The variability described by EOF1 in both the J35-4K run and observations over the Pacific sector during January is dominated by pulsing of the combined eddy-driven/ subtropical jet, though shifting in the position of the jet is also noticeable. Therefore, we feel that the J35-4K model run qualitatively approximates the observed conditions over the Pacific sector.

The synoptic eddies in the J35-4K model run initially reinforce the zonal wind anomalies associated with the leading mode, but this response weakens with increasing positive lag. Our analysis reveals that this positive feedback occurs mainly during the high index phase of EOF1 and is greatly damped during the low index phase. The damped eddy response during the low index phase of the leading EOF is caused by trapping of the eddies within the stronger jet that develops during the low index phase.

Model results in the previous section suggest that the dynamics of the Atlantic and Pacific sectors are broadly similar in the sense that a positive feedback exists between the eddies and the zonal wind anomalies associated with the leading EOF. The positive feedback causes the variability to be dominated by meridional shifting of the eddy-driven jet, that is, annular-modelike variability. Model results also indicate that this feedback mechanism is damped when the zonal jet becomes quite strong and sharp, as observed in the Pacific sector. This implies that in the Pacific sector, annular mode variability, that is, meridional shifting of the jet, is not as dominant. Analysis of the leading mode of variability over the Pacific sector during January supports this contention.

Comparing the leading EOFs over the Pacific sector when the tropospheric jet is strongest [January and February (JF)] against the rest of the winter season [October-April (ONDMA) excluding January and February] yields additional support for our argument. Figure 13 shows the regression of $300-\mathrm{hPa}$ zonal wind anomalies onto the leading PC of the Pacific sector $\langle\bar{u}\rangle$ for the two periods. During the majority of the winter season (ONDMA), the jet maximum, shown by the bold dotted line, is collocated with the node of the leading EOF; thus, the leading EOF over the Pacific sector during ONDMA describes meridional shifting of the jet. When the Pacific jet strength is strongest during JF, though, the jet maximum lies near the center of the negative lobe of the leading EOF. This equates to the variability being dominated by pulsing of the jet strength.

Lorenz and Hartmann (2001, 2003) demonstrated that the eddy-zonal flow feedback is critical for selecting the annular mode as the leading mode of zonal- a) ONDMA $300 \mathrm{hPa}$ zonal wind regression

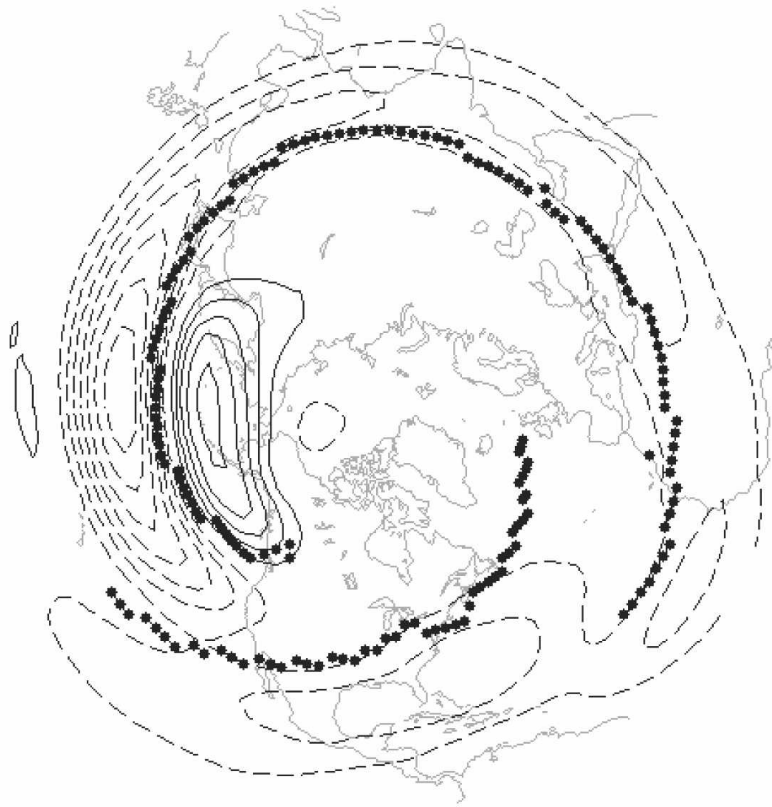

b) JF $300 \mathrm{hPA}$ zonal wind regression

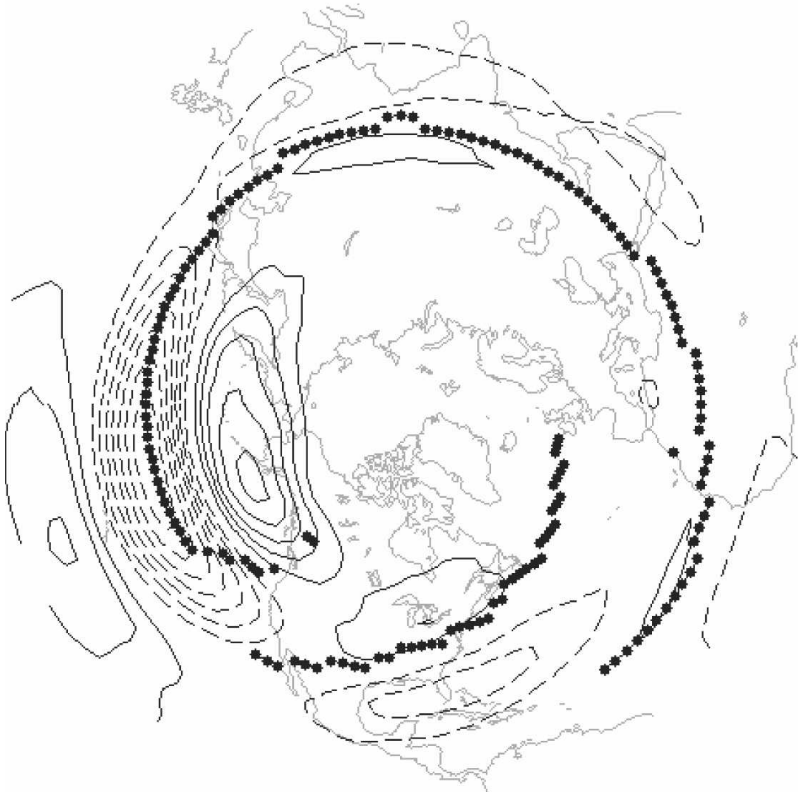

FIG. 13. Regression of 300-hPa zonal wind onto the leading PC: ONDMA and JF. Contour interval is $2 \mathrm{~m} \mathrm{~s}^{-1}$, and the $0 \mathrm{~m} \mathrm{~s}^{-1}$ contour is omitted

mean variability in both hemispheres. This study further demonstrates the importance of the eddy-zonal flow feedback in helping to explain the observed differences in the structure of the NAM between the Atlantic and Pacific sectors during the winter season. Specifically, our model results reveal that the strength of the eddy-zonal flow feedback is stronger for the zonal 
wind distribution over the Atlantic sector than for that over the Pacific sector. The jet structure over the Pacific sector inhibits the necessary wave propagation to produce the positive eddy-zonal flow feedback, especially during January and February. Therefore, the feedback between the transient eddies and the local jet is weaker in the Pacific sector as compared to the Atlantic sector, and this leads to corresponding differences in the strength of the NAM over the two regions.

Codron (2005) has shown that the structure of the SAM also depends on the zonal jet structure during Southern Hemisphere summer. He found that the latitude of the node of the SAM shifts during the summer season, with the node located more equatorward during December than March. Unlike the NAM, Codron (2005) shows that the SAM describes meridional shifting of the jet at all longitudes, which explains the in- creased symmetry of the SAM compared to the NAM. The changes in the structure and variance of the SAM are associated with changes in the strength of the positive feedback between the eddies and zonal flow. These results correspond well with our results for the NAM.

Acknowledgments. This work was supported by the National Science Foundation under Grant ATM0409075.

\section{APPENDIX A}

\section{Initial Zonal-Mean Zonal Wind}

We use the equations in Scinocca and Haynes (1998) to define the initial zonal-mean zonal wind field. The equations are given as follows:

$$
U(z, \phi)=G(\phi)\left[U_{\text {trop }}(z) F_{\text {trop }}(\phi)+U_{\text {strat }}(z) F_{\text {strat }}(\phi)\right],
$$

where

$$
\begin{aligned}
U_{\text {trop }}(z) & = \begin{cases}\Omega z & \text { if } 0 \leq z \leq z_{t} \\
a\left(z-z_{2}\right)^{4}+b\left(z-z_{2}\right)^{3}+c\left(z-z_{2}\right)^{2}+U_{0 t} & \text { if } z_{t} \leq z \leq z_{2} \\
U_{0 t} \operatorname{sech}^{2}\left[\left(z-z_{2}\right) / c_{2}\right] & \text { if } z_{2} \leq z,\end{cases} \\
\Omega & =1.2 \frac{U_{0 t}}{z_{2}}, \\
a & =\frac{-3 U_{0 t}}{\left(z_{t}-z_{2}\right)^{4}}+\frac{3 \Omega z_{t}}{\left(z_{t}-z_{2}\right)^{4}}-\frac{2 \Omega}{\left(z_{t}-z_{2}\right)^{3}}, \\
b & =\frac{8 U_{0 t}}{\left(z_{t}-z_{2}\right)^{3}}-\frac{8 \Omega z_{t}}{\left(z_{t}-z_{2}\right)^{3}}+\frac{5 \Omega}{\left(z_{t}-z_{2}\right)^{2}}, \\
c & =\frac{-6 U_{0 t}}{\left(z_{t}-z_{2}\right)^{2}}+\frac{6 \Omega z_{t}}{\left(z_{t}-z_{2}\right)^{2}}-\frac{3 \Omega}{\left(z_{t}-z_{2}\right)}, \\
F_{\text {trop }}(\phi) & =\operatorname{sech}\left(\frac{\phi-\phi_{2}}{b_{2}}\right), \\
U_{\text {strat }}(z) & =U_{0 s} \operatorname{sech}^{2}\left(\frac{z-z_{1}}{c_{1}}\right) \frac{1+\tanh \left[\left(z-z_{2}\right) /\left(z_{2}-z_{t}\right)\right]}{2}, \\
F_{\text {strat }}(\phi) & =\operatorname{sech}\left(\frac{\phi-\phi_{1}}{b_{1}}\right), \\
G(\phi) & =\tanh \left(\frac{\phi}{5}\right) \tanh \left(\frac{90-\phi}{5}\right) .
\end{aligned}
$$

The stratospheric jet is located at $\left(\phi_{1}, z_{1}\right)$, and its meridional and vertical half widths are given by $b_{1}$ and $c_{1}$, respectively. Here $U_{0 s}$ denotes the amplitude of the stratospheric jet. Similarly, the parameters $\phi_{2}, z_{2}, b_{2}, c_{2}$, and $U_{0 t}$ described the position, width, and amplitude of the tropospheric jet. The above equations are suitable for defining a hemispheric zonal-mean zonal wind field, but a global field is required for model initialization. 
To create a global initial zonal wind field, we define a zonal wind field for the Southern and Northern Hemisphere separately and then merge the two fields together. The following parameters are used for the Southern Hemisphere: $\phi_{1}=-37^{\circ}, \phi_{2}=-45^{\circ}, z_{1}=65$ $\mathrm{km}, z_{2}=12 \mathrm{~km}, b_{1}=30^{\circ}, b_{2}=10^{\circ}, c_{1}=34 \mathrm{~km}, c_{2}=$ $7.5 \mathrm{~km}, U_{0 s}=-70 \mathrm{~m} \mathrm{~s}^{-1}, U_{0 t}=35 \mathrm{~m} \mathrm{~s}^{-1}$, and $z_{t}=7.5$ $\mathrm{km}$. For the Northern Hemisphere, $\phi_{2}$ and $U_{0 t}$ are varied depending on the run, while the rest of the parameters are held constant: $\phi_{1}=60^{\circ}, z_{1}=53 \mathrm{~km}, z_{2}=12$ $\mathrm{km}, b_{1}=16^{\circ}, b_{2}=12^{\circ}, c_{1}=22 \mathrm{~km}, c_{2}=7.5 \mathrm{~km}, U_{0 s}=$ $80 \mathrm{~m} \mathrm{~s}^{-1}$, and $z_{t}=7.5 \mathrm{~km}$.

\section{APPENDIX B}

\section{Zonal-Mean Zonal Wind Tendency}

We use a separate model run to calculate the zonalmean zonal wind tendency. In this model, damping is applied toward the initial state with a time scale of 20 days. The zonal-mean zonal wind tendency is calculated by taking the difference of the initial and final (steady state) zonal-mean zonal wind fields of this run and multiplying by the 20-day damping time scale. Our zonalmean zonal wind tendency qualitatively resembles that shown in Fig. 1b of Sassi et al. (2002). [The zonal-mean zonal wind tendency in Sassi et al. (2002) is calculated from a spectrum of nonstationary gravity waves.] We performed additional simulations using different versions of the zonal-mean zonal wind tendency. Model results remained consistent among all runs.

\section{REFERENCES}

Ambaum, M. H., B. J. Hoskins, and D. B. Stephenson, 2001: Arctic Oscillation or North Atlantic oscillation? J. Climate, 14, 3495-3507.

Andrews, D. G., J. R. Holton, and C. B. Leovy, 1987: Middle Atmosphere Dynamics. Academic Press, 489 pp.

Codron, F., 2005: Relation between annular modes and the mean state: Southern Hemisphere summer. J. Climate, 18, 320-330.

Deser, C., 2000: On the teleconnectivity of the "Arctic Oscillation." Geophys. Res. Lett., 27, 779-782.

Eady, E., 1949: Long waves and cyclone waves. Tellus, 1, 33-52.

Gong, D., and S. Wang, 1999: Definition of antarctic oscillation index. Geophys. Res. Lett., 26, 459-462.

Held, I. M., 1975: Momentum transport by quasi-geostrophic eddies. J. Atmos. Sci., 32, 1494-1497.

— , and A. Y. Hou, 1980: Nonlinear axially symmetric circulations in a nearly inviscid atmosphere. J. Atmos. Sci., 37, 515533.

Holton, J. R., 1983: The influence of gravity wave breaking on the general circulation of the middle atmosphere. J. Atmos. Sci., 40, 2497-2507.

Krishnamurti, T. N., 1961: The subtropical jet stream of winter. $J$. Meteor., 18, 172-191.

Lee, S., and H.-K. Kim, 2003: The dynamical relationship between subtropical and eddy-driven jets. J. Atmos. Sci., 60, 14901503.

Limpasuvan, V., and D. L. Hartmann, 1999: Eddies and the annular modes of climate variability. Geophys. Res. Lett., 26, 3133-3136.

Lorenz, D. J., and D. L. Hartmann, 2001: Eddy-zonal flow feedback in the Southern Hemisphere. J. Atmos. Sci., 58, 33123327.

— and _ 2003: Eddy-zonal flow feedback in the Northern Hemisphere winter. J. Climate, 16, 1212-1227.

McWilliams, J. C., and J. H. S. Chow, 1981: Equilibrium geostrophic turbulence I: Reference solution in a $\beta$-plane channel. J. Phys. Oceanogr., 11, 921-949.

Nakamura, H., 1992: Midwinter suppression of baroclinic wave activity in the Pacific. J. Atmos. Sci., 49, 1629-1642.

North, G. R., T. L. Bell, R. F. Cahalan, and F. J. Moeng, 1982a: Sampling errors in the estimation of empirical orthogonal functions. Mon. Wea. Rev., 110, 699-706.

— , F. J. Moeng, T. L. Bell, and R. F. Cahalan, 1982b: The latitude dependence of the variance of zonally averaged quantities. Mon. Wea. Rev., 110, 319-326.

Panetta, R. L., 1993: Zonal jets in wide baroclinically unstable regions: Persistence and scale selection. J. Atmos. Sci., 50, 2073-2106.

Randel, W. J., and I. M. Held, 1991: Phase speed spectra of transient eddy fluxes and critical layer absorption. J. Atmos. Sci., 48, 688-697.

Rhines, P. B., 1975: Waves and turbulence on a $\beta$-plane. J. Fluid Mech., 69, 417-443.

Robinson, W. A., 2000: A baroclinic mechanism for the eddy feedback on the zonal index. J. Atmos. Sci., 57, 415-422.

Saravanan, R., 1992: A mechanistic spectral primitive equation model using pressure coordinates. Model Documentation, Dept. of Applied Mathematics and Theoretical Physics, University of Cambridge, $36 \mathrm{pp}$.

Sassi, F., R. R. Garcia, B. A. Boville, and H. Liu, 2002: On temperature inversions and the mesospheric surf zone. J. Geophys. Res., 107, 4380, doi:10.1029/2001JD001525.

Schubert, S. D., and C.-K. Park, 1991: Low-frequency intraseasonal tropical-extratropical interactions. J. Atmos. Sci., 48, 629-650.

Scinocca, J., and P. Haynes, 1998: Dynamical forcing of stratospheric planetary waves by tropospheric baroclinic eddies. $J$. Atmos. Sci., 55, 2361-2392.

Shine, K. P., 1987: The middle atmosphere in the absence of dynamic heat fluxes. Quart. J. Roy. Meteor. Soc., 113, 603-633.

Son, S.-W., and S. Lee, 2005: The response of westerly jets to thermal driving in a primitive equation model. J. Atmos. Sci., 62, 3741-3757.

Thompson, D. W. J., 2000: Annular modes in the extratropical circulation. Part I: Month-to-month variability. J. Climate, 13, 1000-1016.

_ , and J. M. Wallace, 1998: The arctic oscillation signature in the wintertime geopotential height and temperature fields. Geophys. Res. Lett., 25, 1297-1300.

— S. Lee, and M. P. Baldwin, 2002: Atmospheric processes governing the Northern Hemisphere Annular Mode/North Atlantic Oscillation. The North Atlantic Oscillation, Geophys. Monogr., Vol. 134, Amer. Geophys. Union, 81-112.

Wallace, J. M., 2000: North Atlantic Oscillation/Annular Mode: Two paradigms-One phenomenon. Quart. J. Roy. Meteor. Soc., 126, 791-805. 